\title{
Index Accessory Extensor and Radials Accessory Carpi Extensor: Anatomical, Clinical and Surgery Relevance
}

\author{
Oliveira JVR, ${ }^{1}$ Almeida Junior E, ${ }^{2}$ Nogueira MS, ${ }^{2}$ Nunes DR, ${ }^{2}$ Santos CNOB, ${ }^{2}$ Reis FP ${ }^{2}$ \\ 'Department of Biomorphology, Human Anatomy for Medicine, Federal University of Bahia (UFBA), Salvador, BA,Brazil \\ ${ }^{2}$ Department of Health, Human Anatomy for Medicine of Tiradentes University (UNIT), Sergipe, SE, Brazil
}

Disclose and conflicts of interest: none to be declared by all authors

\section{ABSTRACT}

Introduction: increased supination and pronation movements was associating with more number of muscles and tendons and could explain the formation of extensors carpal muscles.

Case report: The objective of this study was to describe the anatomical variation not yet described in the tendon of the accessory extensor muscle of the finger index and of the radial accessory carpal extensor muscle, which occurred simultaneously in the same individual, the clinical and surgical repercussions of this and other variations of the extensor muscles of the wrist.

Level of Evidence: IV

Keywords: Anatomical variation; extensor; wrist;supernumerary tendons.

\section{Introduction}

Evolution of the human species for supernumerary tendons

The M. extensors carpi radials have been studying in detail in humans. In mammals, there is marked morphological evolution, with two muscles in humans and one in others mammals (dog, cat, rabbit and sheep) a more or less distinct division of the tendons or muscles. In pentadactyls species many elements represent the plesiomorphism, who believe that the muscle was originally single and are therefore of use in constructing a classification on the evolution basis (Grasseâ, 1971; Cossuand Guintard, 2000). Increased supination and pronation movements have been associated with more number of muscles/tendons in the extensor carpal radials muscle and could explain the formation of extensor carpal radials muscle. The need to extend wrist and throw an object in a precise direction that was the need of the primate evolving to be the human being, could explain the extra extensors seen over the wrist and digits (Bharambe et al, 2017).

Osteofibrous compartments in the hand of the carpal extensor muscles

On the dorsal surface of the wrist is a thickening of the posterior fascia of the forearm called the extensor retinaculumM. tendons. This is the six-compartment ceiling of the extensor tendons. As this retinaculum runs obliquely, from the lateral margin of the bone to the medial border of the styloid process of the ulna, pyramidal and pisiform, it sends septum that attach to the underlying bones form six compartments through which tendons of the extensor muscles of the wrist and fingers pass. Muscles constituting the osteofibrous compartments: - First compartment: Abductor
pollicislongus(APL) and Extensor Pollicis Short (EPS) Second compartment: Long Radial Carpi

Extensor (LRCE) and Short Radial Carpi Extensor (SRCE). - Third compartment: Extensor Pollicis

Long (EPL). - Fourth compartment: Extensor Common Finger (ECF) and Extensor Index (EI). - Fifth compartment: Extensor of the Little Finger (ELF). - Sixth compartment: Extensor Ulnar Carpi (EUC) (Classen and Wree, 2002).

\section{Possibilities in supernumerary tendons}

Most of the anatomical variations in the extensor tendons are asymptomatic initially. However, pain may arise. Thus, the presence of anatomical variations of the tendons in the first dorsal compartments of the wrist raises attention for the diagnosis with static and dynamic exams (Vessal and Rai, 2006). Sometimes only static exams can't identify the variations in the tendons (Subramaniyam et al, 2018) as well as demand for care in clinical and surgical therapy, due to the frequent occurrence of cumulative trauma caused by repetitive efforts, such as by various inflammatory processes, the most common and incapacitating being the stenotic tenosynovitis of

De Quervain. In addition, to fractures of the distal radius where bone irregularities caused at the Lister tubercle level can lead to tendon rupture. Pathological conditions such as rheumatoid arthritis, the tendon loses protection through its synovial sheath, which is affected by the disease, and without this protection the constant friction caused by its passage in the osteofibrous canal leads to rupture of the tendon and an important functional deficit on the hand (SawaizumI et al, 2003; Garcia-Elias, 2004; Tordjman et al, 2018).

Another possibility of a wrist disease is avascular 
osteonecrosis of the lunate, Kienböck disease. Even with etiology still uncertain for this pathology, degenerative alteration occur from the radiocarpal and mediocarpal joint surface, probably caused by bone biomechanical imbalance or rupture of ligaments and blood vessels during a contusion, sprain or subluxation (Lichtman et al, 2010; Fontains, 2015).

Knowledge of the anatomical composition of the posterior compartment of the hand is important to support the biomechanical studies involving the movements of the wrist of the fingers, as well as the therapeutic interventions of pathologies of the region, with physical, pharmacological and surgical agents.

\section{Materials and Method}

The research was making out in the anatomy laboratory and with a favorable opinion of the Research Ethics Committee, under protocol number 0357.0.107.000-11.

The study material of this work consisted of 80 pieces (dissected hands). 64 dissected hands correspond to 32 fetal cadavers and 16 dissected hands correspond to 8 adult cadavers, which were previously prepared by $10 \%$ formalin injection. The dissected limbs belonged to subjects ranging from 28 to 57 years old, and fetus with 22 to 33 weeks of gestational age, a mean of 27.4 $(\mathrm{SD}=3,14)$. The corpses were skin color black $(\mathrm{n}=11)$, skin color brown $(n=16)$ and skin color white $(n=13)$, belonged to both sexes, 22 male and 18 female. The cadavers were placing on a dissecting table, in the position of dorsal decubitus with the upper limb in the median position of supination prone of the forearm. Although the study sample was random, there was no relationship between the anatomical variations found and the prevalence of age, skin color and gender.

\section{The dissection was performing in the following order:}

We initiated the dissection by a transverse incision in the skin. To Distal, to the joint between the phalanges of the fingers followed by another transverse incision in the transition from the distal third of the arm and a longitudinal incision that goes from the thumb to the arm, with space for rebate of the skin covering the myotendinous junction of the dissected muscles. With the Lateral Antebrachial Cutaneous Nerve (superficial branch of the radial nerve, which is sensitive) and the cephalic artery dissected and removed. The preparation continued with the removal of the extensor retinaculum and the identification of the muscles of the osteofibrous tunnels. The muscles were dissecting from the myotendinous junction to their insertions. The normal anatomical state, the presence of anatomical variations of accessory tendons, absence of tendons, duplication of tendons and alterations in the anatomical path were analyzing.
Table 1. Distribution cases of anatomical variations, Age, Sex.

\begin{tabular}{|c|c|c|c|}
\hline Case & Age Variation & Side / Hand & Anatomical \\
\hline $\mathbf{Y}$ & Sex & Right & Left \\
\hline 28 & M & Normal & Normal \\
\hline 31 & $M$ & Normal & Normal \\
\hline 32 & $M$ & Normal & Normal \\
\hline 33 & M & ERAC and EAI & ERAC \\
\hline 34 & $M$ & Normal & Normal \\
\hline 38 & M & Normal & Normal \\
\hline 41 & $M$ & Normal & Normal \\
\hline 57 & $\mathrm{~F}$ & Normal & Normal \\
\hline 28 & $\mathrm{~F}$ & Normal & Normal \\
\hline 29 & $M$ & Normal & Normal \\
\hline 29 & $M$ & Normal & Normal \\
\hline 28 & $\mathrm{~F}$ & ERAC & ERAC \\
\hline 26 & $\mathrm{~F}$ & Normal & Normal \\
\hline 31 & $\mathrm{~F}$ & Normal & Normal \\
\hline 31 & $\mathrm{~F}$ & Normal & Normal \\
\hline 27 & M & Normal & Normal \\
\hline 34 & $\mathrm{~F}$ & Normal & Normal \\
\hline 29 & $M$ & Normal & Normal \\
\hline 25 & $M$ & Normal & Normal \\
\hline 26 & M & ERAC & ERAC \\
\hline 29 & $M$ & Normal & Normal \\
\hline 23 & $\mathrm{~F}$ & Normal & ERAC \\
\hline 23 & M & Normal & Normal \\
\hline 30 & $\mathrm{~F}$ & ERAC & Normal \\
\hline 33 & M & Normal & Normal \\
\hline 32 & M & Normal & Normal \\
\hline 30 & M & Normal & Normal \\
\hline 22 & $\mathrm{~F}$ & Normal & Normal \\
\hline 29 & $\mathrm{~F}$ & Normal & Normal \\
\hline 30 & $\mathrm{~F}$ & ERAC & Normal \\
\hline 26 & $M$ & Normal & Normal \\
\hline 25 & $\mathrm{~F}$ & Normal & Normal \\
\hline 25 & $\mathrm{~F}$ & Normal & Normal \\
\hline 22 & $M$ & Normal & Normal \\
\hline 25 & $M$ & Normal & Normal \\
\hline 30 & $\mathrm{~F}$ & Normal & ERAC \\
\hline 26 & $M$ & Normal & Normal \\
\hline 25 & $\mathrm{~F}$ & Normal & Normal \\
\hline 25 & $\mathrm{~F}$ & Normal & Normal \\
\hline 28 & $\mathrm{~F}$ & Normal & Normal \\
\hline
\end{tabular}




\section{Results}

\section{Muscle Extensor Accessory Index (EAI)}

The EAI found with posterior aspect of the distal third of the radial shaft was the origin. A distal insertion a tendon, which in the region of the second metacarpal bone joint, undergoes a tendinous bifurcation, whose medial band inserts into the posterior face of the proximal phalanx of the second finger and its lateral band in the synovial sheath of the extensor muscle tendon of the thumb, not yet description, Figure 1 and Figure 2.

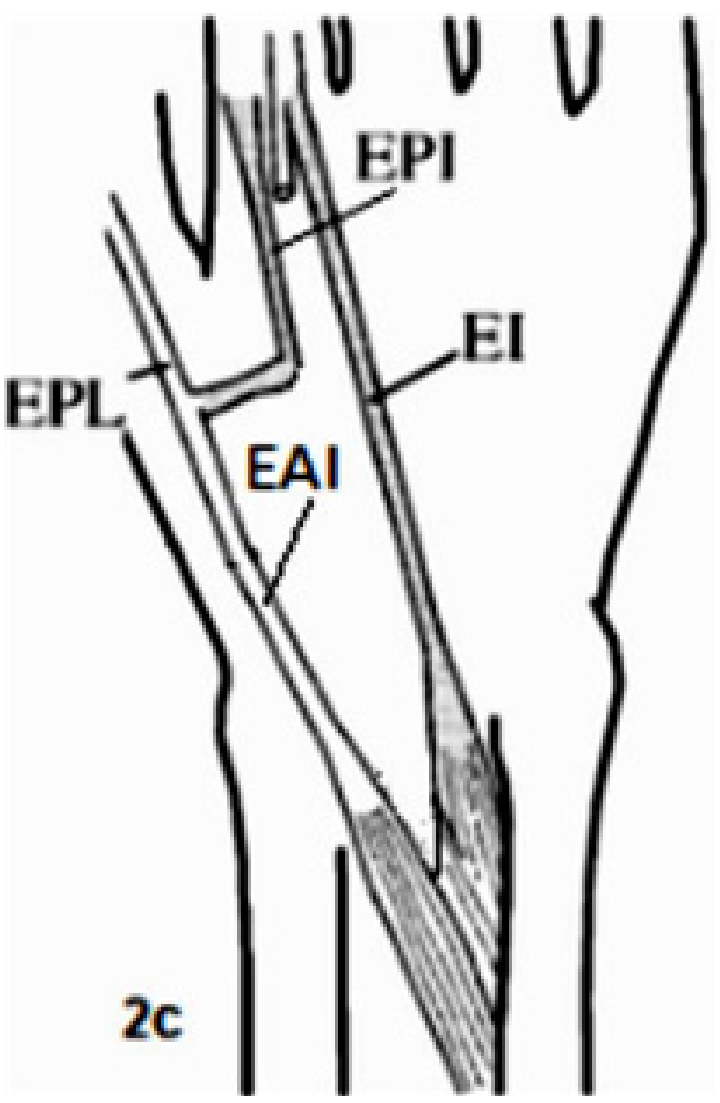

Figure 1. Muscle schematic Extensor Accessory Index (EAI), Extensor Index (EI), Extensor Pollicis Index (EPI), Extensor PollicisLongus EPL).

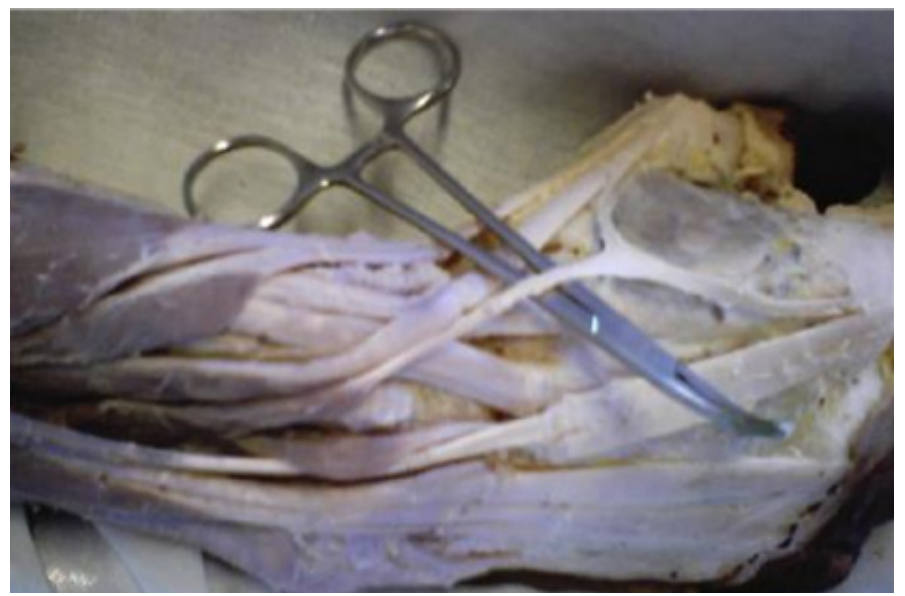

Figure 2. Muscle Extensor Accessory Index (EAI). Side: Rigth.
Extensor Radial Accessory Carpi Muscle (ERAC)

It obtained as origin of the ERAC muscle the lateral epicondyle, in a medial infertile situation to the Extensor Radial Long do Carpi muscle (ERLC). Found the tendon of the Extensor Radial muscle, crossed by the Abdutor Long, Short Extensor and Long Extensor muscles of the thumb in its distal third, and its distal carpal insertion, Figure 3.

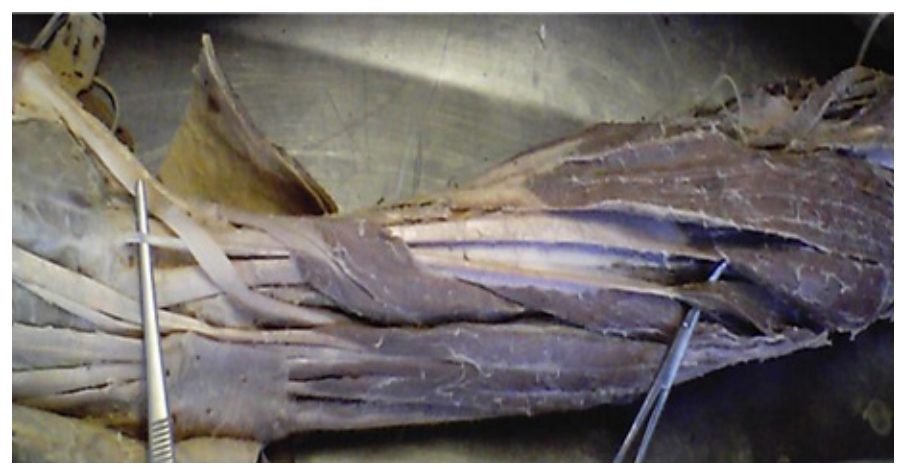

Figure 3. Muscle Extensor Radials Accessory Carpi (ERAC)

Description of the clinical case of appearance of multiple variations in the same individual

The variations to an individual of the white race, of the male gender, it's 33 years old found belonged the EAI with posterior aspect of the distal third of the radial shaft was the origin. A distal insertion a tendon, which in the region of the second metacarpal bone joint, undergoes a tendinous bifurcation, whose medial band inserts into the posterior face of the proximal phalanx of the second finger and its lateral band in the synovial sheath of the extensor muscle tendon of the thumb. An EAI, present unilaterally, right side, no found similar corresponding in the contralateral limb.

Simultaneously in the same cadaver, a muscle ERAC was present bilaterally.

\section{Discussion}

Added one more anatomical variation to the extensor muscles of the Pollicis, according to the classification of Komiyama et al (1999), from the findings of this study; Figure 4 - 2c.

Frequency of appearance of the variations and parallel with the findings

In this study found variation of the wrist extensor muscles: EAI (1,25 \%), ERAC (12,5\%), ERAC bilateral (2,5 \%), unilateral (5 \%). Muscle Extensor Accessory Index (EAI) and Muscle Extensor Radials Accessory Carpi (ERAC) found new variation.

In Casanova-Martínez et al (2014) study found an extensor pollicis and index common with three slips: two toward the index finger and one toward the thumb. In other study found $28 \%$ incidence of variation. 


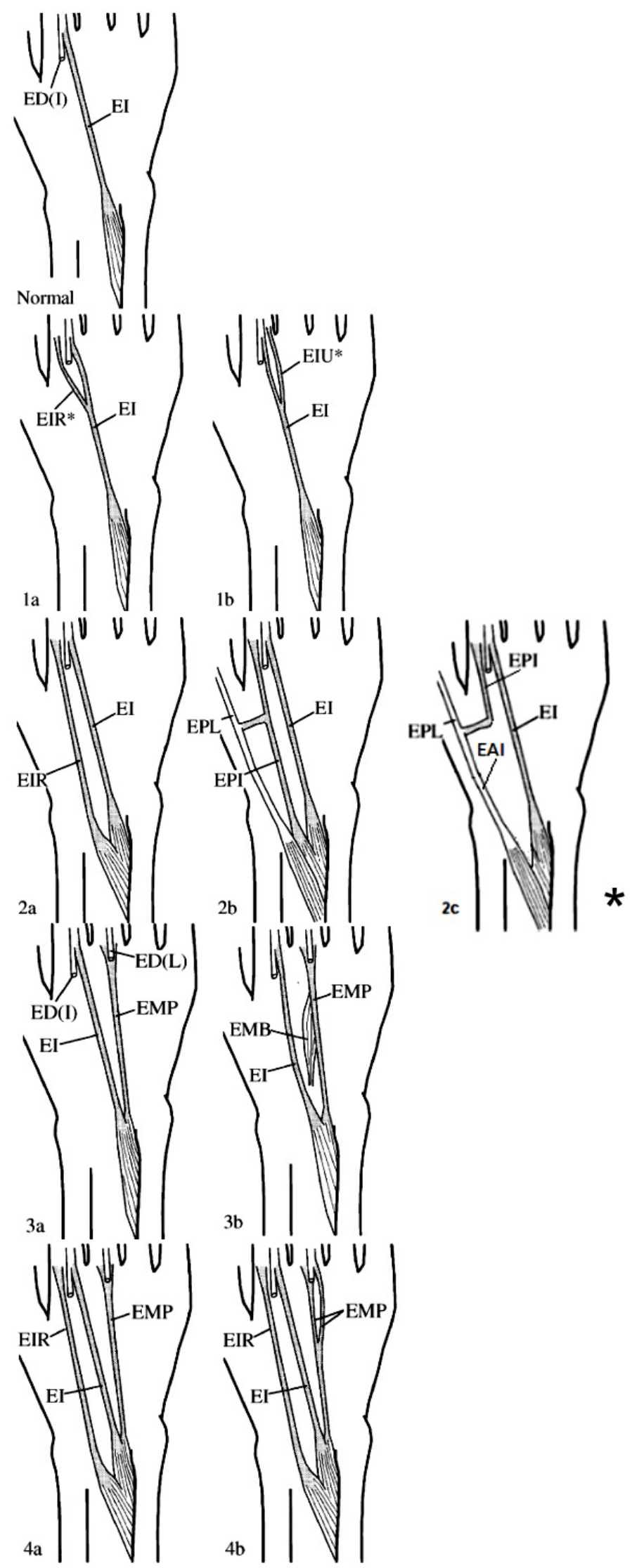

Figure 4. Variation types of the extensor index muscle and tendon (modification of Komiyama et al, 1999). ED (I), extensor digitorum tendon of the index finger, ED (L), extensor digit tendon of the long finger; El, extensor index; EIR, extensor index $\mathrm{S}$ radial; EIU, extensor index ulnar; EMB, extensor medibrevis; EMP, extensor mediproprius; EPI, extensor pollicis et index accessory; EPL, extensor pollicislongus. *EAl, Extensor Accessory Index, (2c).
Variant muscles observed such as extensor carpi radial tertius (4\%), extensor brevis finger (2\%) and extensor finger (4\%), duplication and triplication of extensor digit common tendons to the 2nd, 3rd and 4th digits and $28 \%$ incidence of absence of extensor digit common tendon to the little finger (Bharambe et al, 2017).

In other study found variations of the extensor index muscle examined in 164 hands from 86 cadavers. Anomalous cases exhibiting supernumerary muscles or tendons found in 22 hands. These variations categorized into four types: type 1, an additional tendon slip from the extensor index tendon; type 2, an extensor index radials or extensor pollicis et index accessory; type 3, an extensor finger with or without extensor short; and type 4, an extensor index radial and extensor finger. The extensor finger was the most common variation followed by extensor index radial. (Komiyama et al, 1999).

In our study and other study (Khaledpour et al, 1994; Gümüşalan et al, 1997; Melling et al, 2001; Dhiyaneswaran et al, 2018) there were no clear different in incidence of variations between men and women or between right and left hands. When variations were bilateral, both sides were identical or similar in type.

Clinical and surgical importance of the findings in tendon transposition surgeries

Intertendinous connection may affect the independent movement of the Pollicis and fingers, especially the abductor Pollicis. Although this represents a small percentage of the distribution of tendons of the dorsal hand, knowledge of these anatomical variations and their relationships to intertendinous fascia is critical for clinical decisions because this area is using frequently in treatments related to tendon graft, transfer, and transplantation (Casanova-Martínez et al, 2014). After removal of the musculotendinous unit and decompression the patient recovered fully (Tordjman et al, 2018).

Failure to prevent the radiographic degradation of the wrist, which is closely relating to the evolutionary type of rheumatoid disease, allows a valuable time gain in relation to the eventual implantation of joint replacement arthroplasty or to the eventual arthrodesis of the joint wrist (Garcia-Elias, 2004). On the stenosis tenosynovitis, De Quervain, with a thick sheath, after decompression of the tendon sheath, the pain resolved, and thumb extension improved (Sawaizumi and Nanno, 2003; Türker et al, 2010).

Therefore, it is important to know the composition of the posterior compartment of the hand, as well as its anatomical variations, to understand the movements of the wrist and fingers and to be able to intervene correctly in the pathologies that affect the region.

\section{Funding}

Authors received no financial support for the research, authorship, and/or publication of this article. 


\section{References}

1. Bharambe V, Shevade S, Patel D, Manvikar PR, Bajpayee PG. A study of the extensor tendons of the hand from point of view of evolution. J Anatomical Soc India. 2017, 66: 112-117.

2. Casanova-Martínez D, Valdivia-Gandur I, Golanó P. Extensor pollicis et indiciscommunis with triple slips in a bilateral case of accessory muscles of the hand. AnatSci Int. 2014, 89:250-4.

3. Claassen $\mathrm{H}$, Wree A. Multiple variations in the region of $\mathrm{Mm}$. extensores carpi radialislongus and brevis. Ann Anat. 2002, 184: 489-91.

4. Cossu F, Guintard C. Anatomical and Descriptive Study of the Radial Extensor Muscle (M. Extensor Carpi Radialis). Anat. Histol. Embryol. 2000, 29: 337-343.

5. Dhiyaneswaran S. Subramaniyam, Rajesh Purushothaman, Balajizacharia. Snapping wrist due to multiple accessory tendon of first extensor compartment. Intern J Surgery Case Reports.2018, 42: 182-186.

6.Fontains C. Kienböck's disease. Chir Main. 2015, 34: 4-17.

7. Garcia-Elias M. Resection of the distal ulna: The Darrach procedure. In Surgical Techniques in Orthopaedics and Traumatology. (Eds.) ScientifiquesetMédicales. Paris, Elsevier SAS, 2004: 280.

8. Grasseâ, P. P. Traiteâ de Zoologie. Paris, Masson \&Cie, 1971: tome XVI. fascicule III.

9. Gümüşalan Y, Kalaycioğlu A, Yazar F, Arifoğlu Y, Sinav A. Accessory extensor carpi radialis muscle and interconnecting muscular bundle. ActaAnat (Basel). 1997, 159: 57-60.

10. Khaledpour C, Schindelmeiser J. Atypical course of the rare accessory extensor carpi radialis muscle. J Anat. 1994, 184:161-3. 11. Komiyama M, Nwe T M, Toyota N, Shimada Y. Variations of the extensor indicis muscle and tendon. J Hand Surg. 1999, 5: 575-578. 12. Lichtman D, Lesley N, Simmons S. The classification and treatment of Kienböck's disease: the state of the art and a look at the future. J Hand SurgBri. 2010, 35: 349-354.

13. Melling $M$, Steindl $M$, Wilde J, Karimian-Teherani D. An anatomical variant of the extensor carpi radialisbrevis muscle. Wien KlinWochenschr. 2001, 17: 23-24.

14.Sawaizumi T, Nanno M, Ito H. Supernumerary extensor pollicislongus tendon: a case report. J Hand Surg Am. 2003, 28:1014-7.

15. Subramaniyam S. Dhiyaneswaran, Purushothaman Rajesh, ZachariaBalaji. Snapping wrist due to multiple accessory tendon of first extensor compartment. Inter J Surgery Case Reports. 2018, 42: 182-186.

16. Tordjman D., Pierrart J., Bellity J., Delgrande D., Masmejean E. Accessory extensor pollicislongus: A rare tendon anomaly Extensor pollicislongusaccessoire: une rare anomalietendineuse. Hand Surgery and Rehabilitation. 2018, 37: 60-63.

17. Türker T, Robertson GA, Thirkannad SM. A classification system for anomalies of the extensor pollicislongus. Hand (N Y). 2010, 5: 403-7.

18. Vessal S, Rai SB. Accessory extensor carpi radialisbrevis muscle, a pseudomass of the distal forearm: ultrasound and MR appearances -case report and literature review. ClinRadiol. 2006, 61: 442-5.
Received: March 8, 2021

Accepted: June 18, 2021
Corresponding author

Oliveira Juciele VR

E-mail: juciele.valeria@ufba.br or jucielevaleria@yahoo.com.br 